\title{
FUTURE WAVE PROJECTION DURING THE TYPHOON AND WINTER STORM SEASON
}

\author{
Shinsaku Nishizaki, Waseda University, shinsaku-nisshi@fuji.waseda.jp \\ Ryota Nakamura, Toyohashi University of Technology, r-nakamura@ace.tut.ac.jp \\ Tomoya Shibayama, Waseda University, shibayama@waseda.jp \\ Jacob Stolle, University of Ottawa, jstol065@uottawa.ca
}

\section{INTRODUCTION}

IPCC's AR5 stated that it is more likely than not that the frequency of tropical cyclones (TCs) will decrease and that the intensity of TCs will increase over the Western North Pacific in the late 21st century. Until now, many researchers have tried to project wave climate according to various climate change scenario (Hemer et al., 2013). Most studies focus on the change of mean and extreme wave heights. These indices are important to evaluate the effects on coastal structures in terms of natural disaster prevention. However, the effect of climate change on wave conditions induced by extreme events is still vague. The aim of this study is to evaluate the effects of future climate change on wave conditions from one-month simulations including periods of extreme events based on the pseudo-warming method (Sato et al., 2007) with the most recent IPCC scenario.

\section{METHODOLOGY}

The one-way model composed of Weather Research and Forecasting (WRF) and Simulating Waves Nearshore (SWAN) was used to simulate atmospheric circulation and wave climate, respectively. FiNaL analysis data (FNL) was employed as WRF initial and boundary conditions. The calculation domains were set as large as possible to cover the whole Japanese main islands: Hokkaido, Honshu, Shikoku, Kyusyu, and Okinawa. In Japan, extreme waves usually occur in the Pacific Ocean during the typhoon season and in the Sea of Japan during the winter season. October and December 2014 were selected as calculation periods because two typhoons, Phanfone and Vongfong, landed on the Japanese main islands in October and extratropical cyclones passed the Sea of Japan in December. For future climate conditions, only sea surface temperature (SST) increments were considered. The difference between present and future climate conditions was based on the results of multi-model ensemble with 26 Global Climate Models (multi-GCMs) in RCP 8.5 scenario. The amount of SST increase was set in averaged over 2061-2080 case, ranging from $1.75 \mathrm{~K}$ to $3.24 \mathrm{~K}$ in October and ranging from $1.25 \mathrm{~K}$ to $2.85 \mathrm{~K}$ in December for the largest computational domain.

\section{RESULTS OF WAVE SIMULATIONS}

The model was validated using the actual conditions from October and December 2014. The SWAN results of significant wave heights $\left(\mathrm{H}_{\mathrm{s}}\right)$ were compared with observed data at (a) Shizuoka Omaezaki offshore (Pacific Ocean) and (b) Setana (Sea of Japan). The results were in good agreement with the observed data at location (b) over the whole calculation periods. On the other hand, the results at location (a) during the typhoon periods were less precise because swell outside of the computational domain was not considered. The results of $\mathrm{H}_{\mathrm{s}}$ under present and future climate conditions are shown in Figure 1. Comparing the results between them, the maximum $\mathrm{H}_{\mathrm{s}}$ increased and greater $\mathrm{H}_{\mathrm{s}}$ appeared around the typhoon periods at location (a) in October due to the more intense typhoons (Figure 1a). The minor changes can be seen over the whole calculation periods regardless of wave heights at both of the locations.

Simulated $\mathrm{H}_{\mathrm{s}}$ values were rounded in $0.5 \mathrm{~m}$ intervals and the frequency distributions of both present and future cases are presented in Figure 2. Significant changes could not be observed in October, location (b) and in December, location (a) and (b). The results suggest that winter storm associated waves were less influenced by SST increase. Comparing the distributions between present and future cases, however, the frequency of $\mathrm{H}_{\mathrm{s}}<$ $2.0 \mathrm{~m}$ decreased and $2.0 \mathrm{~m}<\mathrm{H}_{\mathrm{s}}<5.0 \mathrm{~m}$ increased at each location and time frame. In particular, this phenomenon was clearer on the Pacific Ocean in October (Figure 2a). The lower frequency of small $\mathrm{H}_{\mathrm{s}}$ shows the possibility for the changes of the current wave conditions.

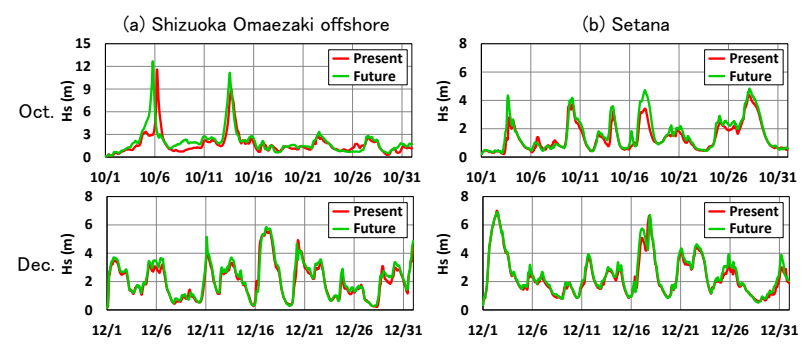

Figure 1 - Significant wave heights $(m)$ of SWAN results under present and future climate conditions.
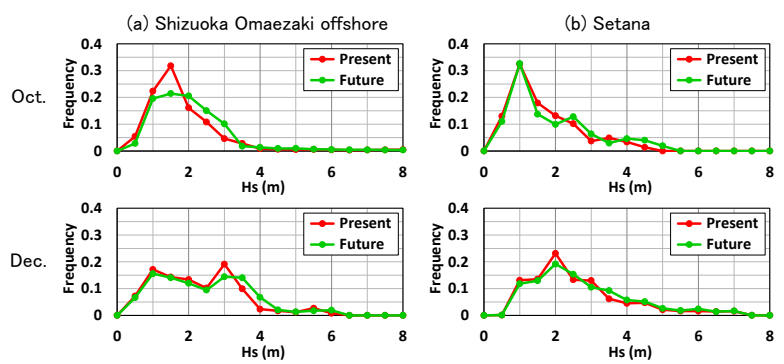

Figure 2 - Frequency distributions of significant wave heights under present and future climate conditions.

\section{CONCLUSION}

Although the SST increase resulted in more intense typhoons and it led to higher $\mathrm{H}_{\mathrm{s}}$ on the Pacific Ocean in October, the effects of SST increase were less important for the extratropical cyclones in December. The lower frequency of smaller $\mathrm{H}_{\mathrm{s}}$ suggests the possibility for more frequent appearance of relatively higher waves.

\section{REFERENCES}

Hemer et al. (2013): Projected changes in wave climate from a multi-model ensemble, Nature Climate Change 3 (5), pp. 471-476.

Sato et al. (2007): Projection of global warming onto regional precipitation over Mongolia using a regional climate model, Journal of Hydrology, vol. 333, pp. 144154. 